\title{
Moving university hydrology education forward with community-based geoinformatics, data and modeling resources
}

\author{
V. Merwade ${ }^{1}$ and B. L. Ruddell ${ }^{2}$ \\ ${ }^{1}$ Assistant Professor, School of Civil Engineering, Purdue University, West Lafayette, IN, USA \\ ${ }^{2}$ Assistant Professor, Department of Engineering, College of Technology and Innovation, \\ Arizona State University, Mesa, AZ, USA \\ Correspondence to: V. Merwade (vmerwade@purdue.edu), B. L. Ruddell (bruddell@asu.edu) \\ Received: 29 January 2012 - Published in Hydrol. Earth Syst. Sci. Discuss.: 29 February 2012 \\ Revised: 23 May 2012 - Accepted: 5 July 2012 - Published: 2 August 2012
}

\begin{abstract}
In this opinion paper, we review recent literature related to data and modeling driven instruction in hydrology, and present our findings from surveying the hydrology education community in the United States. This paper presents an argument that that data and modeling driven geoscience cybereducation (DMDGC) approaches are essential for teaching the conceptual and applied aspects of hydrology, as a part of the broader effort to improve science, technology, engineering, and mathematics (STEM) education at the university level. The authors have undertaken a series of surveys and a workshop involving university hydrology educators to determine the state of the practice of DMDGC approaches to hydrology. We identify the most common tools and approaches currently utilized, quantify the extent of the adoption of DMDGC approaches in the university hydrology classroom, and explain the community's views on the challenges and barriers preventing DMDGC approaches from wider use. DMDGC approaches are currently emphasized at the graduate level of the curriculum, and only the most basic modeling and visualization tools are in widespread use. The community identifies the greatest barriers to greater adoption as a lack of access to easily adoptable curriculum materials and a lack of time and training to learn constantly changing tools and methods. The community's current consensus is that DMDGC approaches should emphasize conceptual learning, and should be used to complement rather than replace lecture-based pedagogies. Inadequate online material publication and sharing systems, and a lack of incentives for faculty to develop and publish materials via such systems, is also identified as a challenge. Based on these findings, we suggest that a number of steps should be taken by
\end{abstract}

the community to develop the potential of DMDGC in university hydrology education, including formal development and assessment of curriculum materials, integrating lectureformat and DMDGC approaches, incentivizing the publication by faculty of excellent DMDGC curriculum materials, and implementing the publication and dissemination cyberinfrastructure necessary to support the unique DMDGC digital curriculum materials.

\section{Introduction}

Hydrology education involves teaching the description, explanation, and prediction of the occurrence, distribution and movement of water in nature. Hydrology is traditionally taught in a classroom using lectures emphasizing the fundamental physical laws of mass, momentum and energy. However, students have difficulty developing a conceptual intuition about complex spatio-temporal systems such as rivers, aquifers, and watersheds based solely on mathematical theories or classroom lectures. Furthermore, applied research and professional careers in hydrology generally involve extensive use of integrated data and modeling applications, so students have a clear need to acquire these skillsets during their education. As a result, there is a need to augment conventional teaching with instructional material that will enable students to explore the integrated spatio-temporal hydrological system and its processes using authentic data and modeling tools. Fortunately, advances in the availability of models, data, and scientific toolsets have created the opportunity to reconceptualize the hydrology curriculum to 
incorporate these new resources. However, a recent study of university hydrology educators found that less than $20 \%$ use community-developed or published materials for the bulk of their classroom activities, indicating that there is a serious dearth of community curriculum development activity in this field (Wagener et al., 2007). In addition, where data and modeling resources are used for hydrology science, technology, engineering, and mathematics (STEM) education, rigorous design of these curricula and assessment of the impact of this pedagogical approach on students' learning are lacking.

The information technology revolution has created tremendous opportunities for science and learning, but these opportunities have not been adequately exploited to transform the quality and depth of STEM education. While the traditional classroom with lecture-format pedagogy plays a critical role in delivering hydrology concepts to students, there is a need to explore how these traditional approaches can be augmented with new pedagogies that include the use of digital data, simulation tools and visualization tools to enhance students' learning. In an effort to explore the resources that exist at the community level to adapt these new tools and methods for teaching hydrology, the authors have undertaken an initiative seeking the input of the university hydrology education community through two surveys and one workshop. The topics covered by the surveys and workshop include existing efforts, availability of data and modeling tools, and the interest of the university hydrology education community in incorporating these new methods into the university hydrology curriculum. The long-term goal of this emerging community effort is to develop a data and modeling driven geosciences cybereducation (DMDGC) curriculum and curriculum materials for university hydrology education applications. The objective of this paper is to summarize findings from this ongoing community effort, and propose ways of moving forward based on the community consensus identified by the surveys and workshop. The paper will first introduce background information including a literature review of existing efforts, followed by details related to the results of the survey and workshop for members of the university hydrology education community of practice, and conclude with a summary of the community's recommendations regarding a way forward. This opinion paper focuses on the university hydrology education in the United States, but bears relevance to the global hydrology community's challenges and interests. While this paper touches on the broader and essential issues of integrating these hands-on DMDGC materials with the traditional curriculum and of online engineering education issues more generally, the scope of this paper is focused specifically on identifying community-specified design criteria for a cyberinfrastructure supporting the publication, discovery, and adaptation of community-based DMDGC curriculum and materials for university hydrology education.

\section{Background}

\subsection{Challenges and opportunities in cybereducation and the geosciences}

The improvement of STEM education in the US has been the goal and focus of dramatically increasing volumes of funded research since the 1990s. A series of landmark reports describe the state of knowledge and grand challenges in STEM education. Duderstadt (2007) provides a roadmap to the future of engineering education, including increasingly practice-based and interdisciplinary engineering experiences for university undergraduates. The National Academy of Sciences' (2007) report highlights the importance of dramatically increased productivity and innovation in STEM fields, and the role of integrated approaches to teaching STEM concepts and toolsets in preparing a generation of US students to be more productive and innovative. The National Academy of Engineering's (2005) report and the National Academy of Science's (2004) report emphasize the centrality of information technology and connectedness between interdisciplinary concepts and tools. All of these voices point to a growing awareness that STEM education needs to be driven by focused, community-based efforts to systematically study and improve STEM education, especially at the university level.

The university educational community is beginning to respond to these calls for action. For example, the recent Presidents of the American Society for Engineering Education (ASEE) (Melsa et al., 2009) are sponsoring an effort to survey and synthesize the state of the engineering education profession. Community recognition of the need for action is essential, because it is not possible to educate the engineers and scientists of 2020 without better equipping and supporting the science and engineering professor of 2020 (Morell et al., 2010). Equipping the next generation of science and engineering professors will involve a broader understanding and prioritization of Boyer's (1990) "dimensions of scholarship" within the university and the professorate, so that the necessary time and energy are focused on improving and rigorously assessing pedagogies, teaching, and especially the creation of new "learning systems" (Special report, 2010) necessary for community-based collaboration on the development and delivery of better integrated STEM educational strategies.

A report by the US National Science Foundation's (Borgman et al., 2008) Task Force on Cyberlearning established a series of recommendations for the NSF's strategies to foster learning in a networked, digital world, notably including (a) the creation of "cross-disciplinary communities of cyberlearning researchers and practitioners", and (b) fostering "shared, interoperable designs of hardware, software, and services" for cyberlearning activities. The Task Force's report also poses several research questions in relation to leveraging of the best of cyberlearning advances, benefits of technology for science learning, life cycle of new 
resources, and sustainability of new innovative technologies for education.

The NSF Task Force on Cyberlearning (Sect. 3.3.2) expresses a concern that the "data deluge" (NSF Cyberinfrastructure Council, 2007) has not been harnessed and adequately translated into STEM learning outcomes. The chief barrier to use of computational models in education is cited as "scalability", which translates as the fitness of cybereducation approaches for use by educators who lack the resources to provide expert programming and technical support for those approaches. To solve the scalability challenge, three practical criteria for DMDGC curriculum materials' best practices are formulated by the Task Force: (i) easy experimentation that requires no programming or operating system knowledge of students or educators; (ii) a high level of interactivity to provide effective feedback and hold attention; and (iii) classroom activities that involve models and data embedded in traditional classroom learning.

Efforts have been made by the international educational community of practice to take steps toward implementing the best practices of scalability in the supporting cyberinfrastructure and institutions of the educational community. The principle of free, openly licensed open educational resources (OER) was established by the UNESCO in 2002 for the purposes of promoting international sharing and democratization of educational resources for the benefit of the developing world. Around the same time, the Massachusetts Institute of Technology implemented its OpenCourseWare (OCW) initiative that posts the complete content of thousands of courses on the Internet, available without charge; hundreds of other universities have since joined this initiative and contributed course content at the undergraduate level. More recently, the National STEM Digital Library (NSDL) has emerged from a crowded community of peer "digital library" hub organizations as the leading hub of a large and growing federation of US niche communities of educational practice, providing long-term archival mirroring and federated resource search services for more focused niche-community portals and "Pathways to the NSDL", and their learning materials. Within this federation, smaller centers such as the Science and Engineering Resource Center (SERC) provide focused editing and publication services for specific projects in their disciplinary domains and provide the "pathways" or portals to the NSDL.

Some recently published examples of STEM cybereducation learning applications include visual representations of links in algebra and calculus (Kaput et al., 2007), uses of scientific visualization for complexity investigations (McKagan et al., 2008), "Microworlds" for learning computational thinking (DiSessa, 2000), and hundreds of others since the inception of the Internet and the microcomputer revolution. However, as explained by the Learning in the Borgman et al. (2008) report, many cybereducation efforts in the first two decades of the World Wide Web (WWW) have failed to achieve fully scalable and sustainable outcomes because the scalability of these efforts had not yet become self-evident during the short life cycle of those initiatives. We argue that the most common scalability/sustainability errors are "dead portals" where a niche community's short-term efforts to develop curriculum materials languish largely undiscovered and without ongoing maintenance, and "monolithic tutorials" which provide comprehensive instruction on a complex sequence of cognitive, theoretical, and modeling tasks that are tightly coupled and therefore difficult to adapt or update when software tools are upgraded or the application context is shifted. Both errors usually lead to a needlessly rapid (usually less than $5 \mathrm{yr}$ ) expiration or obsolescence of current DMDGC curriculum materials, which is an unacceptable fate for otherwise exemplary STEM cybereducation projects that take so much time and money to develop. By contrast, traditional curriculum materials like textbooks appear to make a much more lasting contribution. We argue that the difference in longevity and impact between traditional and cybereducation curriculum materials is due to the relative durability of the information format of textbooks (i.e., printed on paper in a universally understood and temporally stable written language) and the relative maturity of the dissemination infrastructure for traditional printed materials (i.e., libraries, publishers, bookstores and the relatively static conceptual content). Therefore, if the problem and challenge for STEM cybereducation curricula is related to the usability and transferability of the format of the curriculum materials and to the lack of adequate infrastructure for its maintenance and dissemination, then these are areas that warrant careful attention from the STEM community, as this community strives to make fundamental advances in the quality and impact of its curriculum via cybereducation approaches.

\subsection{Review of cybereducation collaboration and dissemination initiatives}

A number of notable efforts have been made to address the problems of information format and dissemination infrastructure for STEM education, with some of the most important efforts aimed at university-level cybereducation applications. The US National STEM Digital Library (NSDL) was specifically cited by the NSF Task Force on Cyberlearning (Fostering Learning in the Networked World, Borgman et al., 2008) as a resource of value for undergraduate educators, and is therefore understood to be a critical dissemination interface for any platform developed or adopted for DMDGC purposes. The NSDL maintains a robust dissemination cyberinfrastructure that mirrors content provided on a federation of pathways (e.g., the K-Gray Engineering Pathway http: //www.engineeringpathway.com/ep/, and the Science Education Resource Center - SERC - http://serc.carleton.edu), which are community-specific educational content portals, and allows users to discover content published by any of those portals. The NSDL is continually evolving its content access mechanisms through a network of engaged partners 
such as the the "Instructional Architect" system developed by Utah State University and the Digital Library for Earth Science Education (DLESE, www.dlese.org). Similar activities in Europe include the Euro Aquae consortium and UNESCOIHE's initiative on hydroinformatics training (Popescu et al., 2009).

However, these dissemination systems do not create their own content-specialized communities of educational practice (e.g., for oceanography, the Enduring Resources for Earth Sciences Education - ERESE - http://earthref.org/ERESE/). The goal of the hydrology DMDGC community's dissemination efforts should be to create excellent curricular materials, and disseminate those materials using the broader existing cyberinfrastructures. The hydrology DMDGC community has unique needs that cannot be filled by existing dissemination systems. DMDGC curricula go beyond static materials, and begin to enter the territory of learning management systems (LMS, e.g., the Advanced Distributed Learning network or ADLnet, or Edu 2.0, www.edu20.org) and course management systems (CMS, e.g., Moodle - www.moodle. org). Systems like the Multimedia Educational Resources for Learning and Online Teaching (Merlot, www.merlot.org) allow educational users to browse many educational materials, contribute their own materials, and create their own personal collections of curriculum materials for use in specific courses. Perhaps the best example of a highly polished and well-integrated LMS and CMS is operated by the K-12 oriented National Science Teachers Association (www.nsta. org), which delivers thousands of science content modules, each with its own outcomes and pre/post assessments, indexed by grade level, topic, and state-by-state educational standards, and all available through a personalized course management system (learningcenter.nsta.org). The ideal hydrology DMDGC will incorporate elements of these dissemination, learning content management, and course management systems, utilizing as many shared services as possible, while adding focused capabilities to support learning content that integrates visualization, data access, and modeling activities with seamless assessment and formative feedback.

The literature clearly highlights the role of data, simulation and visualization tools in preparing the next generation of hydrologists. Several ongoing efforts are trying to develop new tools and collaborative environments for educators to build a bridge between traditional teaching and new technology. However, the issue of scalability and sustainability needs consideration to create a long lasting impact on delivering education. Keeping these findings in mind, our objective is to seek community input on how such an infrastructure can be built, and what educational tools or materials need to be developed to make it useful in hydrology classroom. This objective is fulfilled through organizing a community workshop, and the details are described in the following sections.

\subsection{Review of existing data and modeling based hydrology education initiatives and toolsets}

The hydrology geosciences and engineering communities have already begun to assemble some of the elements of the desired educational framework for undergraduate hydrology education, but the work is in an early stage. As reviewed by Manduca et al. (2008), the geoscience community needs to hold a conversation on teaching methods and shared materials; this conversation is beginning at hubs like the Teaching Quantitative Skills in the Geosciences website (http:// serc.carleton.edu/quantskills/index.html). The community is just beginning to build shared hubs for the development and dissemination of community-authored educational materials, and, although some excellent educational materials already exist in specific topical areas of hydrology engineering and geosciences, these materials have not been integrated together into coordinated curricula with community-standard learning outcomes, or implemented with integral formative feedback and learning assessment mechanisms that will facilitate the formal study and improvement of the curriculum as a whole. Significant barriers remain to a shared hydrology community resource, including immature frameworks for the sharing and integration of intricate DMDGC curriculum materials, lack of a community consensus on defined core educational outcomes at the various K-12 and university levels, cultural differences between the engineering and geoscience application domains of hydrology and their affiliated disciplines (e.g., atmospheric science, geology, biogeochemistry), and a substantial bifurcation between "water quantity" (sometimes called "water resources") and "water quality" (sometimes called "environmental") curricula. Below we highlight selected existing efforts that bear relevance to the development of a community framework for traditional, online, and data and modeling based hydrology education at the undergraduate university level in the US, and the closely associated pre-collegiate and post-graduate levels. The international hydrology community is already engaged in most of these efforts, and is therefore implicitly included in the discussion.

Many excellent individual contributions have been made to develop specific granular curriculum materials, and it is likely that the summed total of these contributions covers nearly the full spectrum of possible content, style, and pedagogy for hydrology education. However, these individual contributions remain largely isolated and un-integrated with a community framework for curriculum development, and are therefore difficult for the workshop's participants or the broader community to identify or include in a review. Integrating these valuable individual contributions as published contributions to the broader community curriculum is the ultimate goal for the development of community cyberinfrastructures and collaboratory frameworks, and it is assumed that these contributions will eventually be discovered and 
integrated into their proper place once the right communitydriven systems are in place.

Three types of toolsets are generally used in hydrologic modeling and data analysis: (Type 1) a computing environment for processing data (Excel/ArcGIS), (Type 2) a toolbar or extension added to a computing environment, and (Type 3 ) a numerical model. The first type of tool may be commonly used in several hydrology courses, but Type 2 is not widely used. Type 3 tools (numerical models) are employed by researchers/educators, and require expertise, familiarity with the model, and their application in their study watershed context. Existing hydrology DMDGC toolsets can be classified into these three categories.

The results of the community workshop and surveys (see Sects. 3 and 4) generally indicate that Type 3 (numerical modeling) tools are desirable for integration into the university classroom in the information age, but that this type of tool is challenging to utilize in the undergraduate classroom and is currently most used in a graduate context (confirming observations from Abbott et al., 1994). The workshop and survey results also indicate that online resources and environments for hydrology and geosciences education are desirable, but that peer and student-instructor interaction and the learning curve and time commitment associated with online courses are major challenges (confirming conclusions by Popescu et al., 2012). The international hydrology community, notably UNESCO-IHE, has experimented with online and computer-based education methods since the beginning of the Internet and personal computing era, and this experience has provided some promising insights and results motivating the development of improved online and numerical educational approaches (Price et al., 2006). A decade ago, a pan-European hydrology experiment placed groups of students from different countries in an information-sharing collaborative Internet environment to develop their teamwork and digital collaboration skills (Molkenthin et al., 2001). Five years ago, the UNESCO-IHE implemented an online course in floodplain management that is used in classrooms around the European Union (Price et al., 2007). Recently, the European Commission's TENCompetence online educational environment was used to implement a water resource decision support system course targeting global professional learners in the developing world (Jonoski and Popescu, 2012). Finally, UNESCI-IHE has created a Moodle virtual learning environment to deploy a number of online courses and a master's program in water resources (http://ecampus.unesco-ihe. org/m19/, accessed 18 May 2012). In summary, the accumulated experience of the international hydrology education community is generally consistent with the broader literature concerning the challenges and opportunities associated with online learning and the use of computerized tools in STEM education; excellent online courses and materials are available, but they are not generally integrated into an adaptable community-based publication and dissemination system that would facilitate solutions to the common challenges preventing the widespread adoption of DMDGC approaches in the hydrology classroom.

A collection of online hydrology resources is available from a variety of sources. The Massachusetts Institute of Technology (MIT) sponsors the Star:Hydro hydrology modeling curriculum, which is an open, interactive modeling and visualization curriculum emphasizing distributed surface water hydrology and statistics (http://web.mit.edu/star/ hydro/index.html). Star:Hydro has been utilized by a number of educators around the USA for the past decade, and has been a valuable resource for the community. The University Center for Atmospheric Research's (UCAR) COMET program is a widely utilized online training program that provides both free educational materials and paid residential and online courses for hydrology, emphasizing the meteorological aspects of hydrology (http://www.comet.ucar. edu/). The Community Surface Dynamics Modeling System (CSDMS, http://csdms.colorado.edu and http://csdms. colorado.edu/wiki/Hydrological_Models) provides free access to online modeling of the Earth's surface in a highperformance distributed computing environment, with models contributed by the broader community and eventually integrated into the CSDMS. The CSDMS is growing and may eventually become very important for geoscience cybereducation. The Teaching Quantitative Skills in the Geosciences website (http://serc.carleton.edu/quantskills/index.html) provides pedagogical advice and specific resources for quantitative geoscience teaching at a variety of levels, including the undergraduate university geosciences classroom. These tools and resources, along with others emerging across the World Wide Web, will continue to add value for DMDGC approaches.

A heavily used and publicly available resource is the US Army Corps of Engineers' Hydraulic Engineering Center's (USACE-HEC) modeling toolset (http://www.hec. usace.army.mil/); especially HEC-RAS and HEC-HMS and their GIS-enabled versions (Geographical Information Systems, GIS) have motivated the development of a number of hydrology DMDGC curriculum materials, including those of the authors (see GIS and Water Resources Modeling Workshop materials at http://web.ics.purdue.edu/ $\sim$ vmerwade/tutorial.html). The HEC's modeling systems have reached a nearly universal level of exposure in the engineering hydrology community (along with the popular SWAT model), and are therefore a common toolset for DMDGC activities in undergraduate and graduate hydrology courses.

Last but not least, the Consortium of Universities for the Advancement of Hydrologic Science, Inc. (CUAHSI, www.cuahsi.org) leads an education and outreach initiative that has organized videos, debates, seminars, hydrologic literacy standards (satisfying the NSF's Earth Science Literacy Initiative - ESLI - in the hydrology area), and a database of hydrology-related education programs in the USA. CUAHSI also leads a Hydrologic Information System (HIS, http:// 
his.cuahsi.org), which has succeeded in providing standardsbased and service-oriented access to a wide variety of hydrologic data sources in the USA. CUAHSI sponsors the MOCHA curriculum initiative (see below) and the HydroHUB online seamless modeling environment for hydrology (www.cuahsi.org/hydrohub/). The ArcHydro data model and toolsets and their derivative versions (e.g., the CUAHSI HIS Observations Data Model), jointly developed with cooperation from CUAHSI HIS leadership and the ESRI GIS company, are also supported by CUAHSI's HIS project. Any hydrology DMDGC efforts should ideally be executed in correspondence with CUAHSI, owing to CUAHSI's central role in the USA hydrology community's data interoperability (HIS), modeling (HydroHUB), and education (MOCHA) initiatives.

The Modular Curriculum for Hydrologic Advancement (MOCHA, www.mocha.psu.edu) was established to create a community-driven curriculum based on PowerPointformatted modules covering standardized university-level hydrology outcomes in a traditional hydrology course, including assessments and pedagogically compatible module design. This community aims to establish a Hydrology Body of Knowledge (HBOK) over time by leveraging community input via contributed modules. The community now boasts hundreds of members throughout the world and is publishing its first modules. We suggest that hydrology DMDGC activities could mirror MOCHA community efforts by providing problem-based, computerized, data-and modeling-driven modules to complement the traditional lecture-based curriculum and reinforce MOCHA-style learning module outcomes.

\section{CUAHSI survey of the STEM cybereducation state of practice in the university hydrology education community}

Hydrology in the US is taught at undergraduate and graduate level in multiple disciplines including civil engineering, geological sciences, Earth sciences, atmospheric sciences, and agricultural engineering. Undergraduate hydrology courses are mostly taught as upper-division courses designed for students pursuing one of these disciplines as their major curriculum. In addition, most undergraduate courses are introductory courses with little or no emphasis on data and modeling driven teaching. Data and models including GIS are introduced in some graduate level classes across the nation, but the number of schools that offer such classes is limited. In January 2010, with the assistance of the authors, CUAHSI conducted an informal hydrology community survey with three objectives: (i) assess the current state of data and modeling driven curriculum in hydrology; (ii) gauge the level of support for an effort to develop data and modeling driven curriculum material; and (iii) get input on issues that the community currently faces in adopting data and modeling driven curriculum teaching in hydrology. A total of 120 university hydrology educators (approx. 100 from the
US) with background in multiple disciplines, including engineering and science, participated in this survey. A summary of key results from this survey is in Table 1 .

Table 1 indicates that cybereducation approaches become heavily utilized at and above the upper undergraduate level (Q.3). The most common toolset that is used at upper undergraduate level is Microsoft Excel (see response to Q.5). More advanced approaches, including data pre-processing, numerical modeling and spatial visualization, do not become heavily utilized below the graduate level of the curriculum. The use of ArcGIS, Matlab and other more advanced modeling tools is mostly incorporated in graduate level hydrology courses. The need for curriculum material that involves the use of field or public domain data, modeling and visualization is clearly highlighted in responses to Q.6.

Considering the extensive use of authentic data, integrated modeling, and geospatial visualization in research applications and in the professional world, training in these approaches is becoming necessary for a successful career in hydrology. For this reason alone, it seems reasonable to suggest a strategy of supplementing the traditional hydrology curriculum with the latest data and modeling approaches. However, adopting data and modeling tools in teaching is not easy for instructors. As found in survey Q.7, instructors who want to use computing tools in their courses face several practical problems including (i) negotiating a steep learning curve, and then staying up-to-date with the latest developments; (ii) creating additional teaching material, which is not always available in books and must be extracted from hundreds of pages of user manuals; (iii) collecting or creating datasets to feed the computing tools; and (iv) the lack of an organized user community precludes investment by software companies in tools to service the needs of hydrology geosciences educators. Unavailability of computing tools in the curriculum hinders students' ability to go beyond text book knowledge to explore the field in depth through exploratory learning. Developing instructional tools for STEM cyberlearning is a large added time investment by the instructor, which is often impossible to achieve given time constraints. The most appropriate way to address this issue is to adopt a system where a community of educators (not individuals) can collectively contribute tools, teaching materials and data, which can be adopted by any member of the community.

\section{The 2010 hydrology cyberlearning workshop}

In order to obtain the input of both the geoscience and engineering hydrology communities and build consensus on priorities and paths forward for DMDGC approaches in university hydrology education, a workshop titled "Data-Driven Cyberlearning for Geoscience and Hydrology Education" was held in conjunction with the 2010 CUAHSI annual meeting on 22 July 2010 in Boulder, CO. A list of workshop participants and their expertise is provided in the Supplement. 
Table 1. Summarized results of the 2010 CUAHSI community survey on cyberlearning and data and modeling driven curriculum for the university hydrology classroom.

\begin{tabular}{ll}
\hline Question & Response \\
\hline (1) Background & Science (44); Engineering (26); Both (43) \\
\hline (2) Respondent teaching level & Lower Undergrad. (17); Upper Undergrad. (74); Grad. (98) \\
\hline $\begin{array}{l}\text { (3) Level at which data and modeling are currently used } \\
\text { instruction* }\end{array}$ & Lower Undergrad. (11); Upper Undergrad. (62); Grad. (86) \\
\hline $\begin{array}{l}\text { (5) Software frequently used } \\
\text { (6) What type of data and modeling would you utilize in your class if } \\
\text { high quality free curriculum material were available }\end{array}$ & $\begin{array}{l}\text { GIS analysis and visualization (79); hydrologic modeling (77); } \\
\text { data access and pre-processing (70); custom modules (67); } \\
\text { tutorials on how-tos for modeling (62); online lectures and } \\
\text { webcasts (51) }\end{array}$ \\
\hline (7) Constraint in using data and modeling & $\begin{array}{l}\text { Time commitment (56); steep learning curve (51); lack of } \\
\text { access to easily adoptable teaching material (31); difficulty in } \\
\text { keeping up with technology (26) }\end{array}$ \\
\hline
\end{tabular}

* In written comments, respondents indicated a consensus view that the data and modeling tools should augment, but not replace the traditional teaching methods.

The format of the one-day workshop included presentations in the morning session followed by group discussions. The workshop had the following four objectives:

1. Identifying specific needs for cross-cutting data, modeling, and visualization digital resources that would be valuable for the broader geosciences education community at the upper and lower division undergraduate hydrology education.

2. Strategizing on how to bridge the gap between datadriven applications in major focus area upper division undergraduate education and those in other levels of education (emphasizing lower division undergraduate and community college applications).

3. Specifying key design criteria for a community cyberinfrastructure by which instructors can discover, download, publish, interconnect, modify, review, and collaboratively develop curriculum materials for data-driven cyberlearning in the geosciences.

4. Identifying the best ways to train the teaching community on the effective use of data-driven curriculum materials, to achieve broad impact and dissemination of this approach.

Before the workshop, a pre-workshop survey was conducted to get participants' input on objectives, and to develop focus questions for the break-out sessions. The first session in the morning included a presentation on Modular Curriculum for Hydrology Advancement (MOCHA), a brief presentation of the pre-workshop survey results, and a demonstration of existing online curriculum sharing and dissemination systems. The participants then divided into groups to address two challenges: (A) design learning modules, and (B) sesign the online learning and curriculum development environment). The results of the survey and the workshop discussions follow.

\subsection{Workshop participants survey}

This pre-workshop survey was specifically designed to get participants' input on each objective of the workshop. In addition to sending the survey to all workshop participants, other individuals who expressed interest in this effort, but were unable to participate in the workshop, were also invited to participate in the survey. The survey was completed by 37 participants. A brief summary of the survey results in relation to each workshop objective is provided below.

\subsubsection{Cross-cutting community resource needs}

Several analysis tools were identified as useful for hydrology instruction. Although some of them are public domain (e.g., QGIS, S, R, uDig, PostGIS, etc.), the most commonly used tools such as ArcGIS, Matlab and Excel are proprietary but widely available in universities. The importance of 2-D and 3 -D visualization for computational discovery and understanding of physical hydrology was emphasized in the survey results. Availability of public domain data and tools was identified as one of the desired attributes of instructional resources. The community generally believes that freely available toolsets are preferable to proprietary toolsets. However, the authors note that it is not always possible or desirable to utilize purely open-source and freely available materials. 


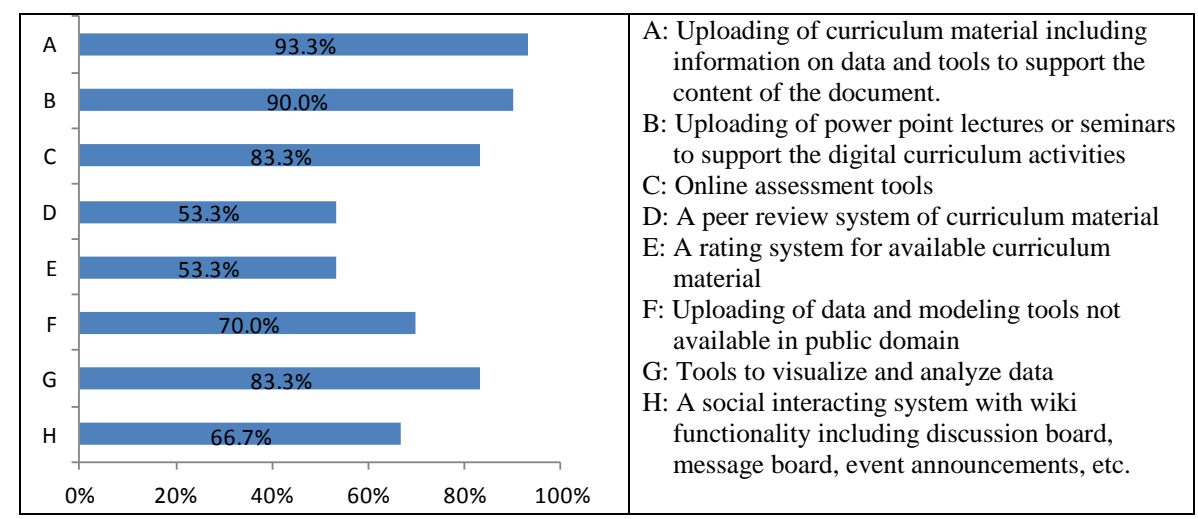

Fig. 1. Percentages of workshop participant survey respondents $(N=37)$ rating specific learning community cyberinfrastructure capabilities and design criteria as important for their personal applications.

Proprietary tools are sometimes desirable, particularly when they are an industry standard. The difficulty in using proprietary materials, of course, is the cost, as well as the fact that the university and the corporate partner may be natural competitors in this educational context. It is worth keeping in view the possibility of partnership with corporate providers of software and training, and to allow these corporate partners to participate in community $\mathrm{CI}$ and curriculum dissemination activities. This suggestion is similar to the wellaccepted use of expensive proprietary textbooks in the lecture environment, where the instructor integrates proprietary textbook material into the course and serves as a personal guide or an interpreter of the material for the student's specific context. Participants also identified some weaknesses for currently available data and tools. Weaknesses associated with data mainly included a lack of datasets for students to work within their local watersheds, incompatibility in formats/coverage/resolution of different datasets, and a severe computational burden of pre-processing before using for analysis or modeling.

\subsubsection{Bridging the gap to upper level hydrology education}

There was a general consensus among respondents that most hydrology concepts can be taught using data and modeling tools, with appropriate level of learning objectives and computing skill expectations at different teaching levels (lower or higher undergraduate or graduate level). Topics that can be taught using computerized techniques include water balances, water fluxes, and graphical visualization of different hydrological concepts or theories (equations). Besides hydrology concepts, computerized instruction can also expose students to issues associated with modeling such as scale, parameterization, feedback mechanisms between hydrologic components, and uncertainty in input data and model results. It is important for students to think about hydrology without computers, and how computers can be used to simulate the system. To develop students' curiosity for hydrology, field trips in conjunction with traditional and modern computerized instruction are important. Visiting sites where instrumentation generates scenario data is particularly desirable. Engaging students in projects based on real-world issues with outcomes that can be compared and contrasted will create questions in students' minds that can be answered through computerized methods.

\subsubsection{Establish cyberinfrastructure design criteria}

If a cyberinfrastructure is developed to create a community of instructors, uploading and downloading of curriculum material is the most highly identified function that the participants would like to see implemented. This top priority is followed by online assessment, visualization and analysis tools, uploading of data and modeling tools, and social interaction systems. Peer review and rating systems for the curriculum received the least interest from participants (Fig. 1). Many workshop attendees expressed surprise at this last-place result for curriculum material publication and ratings, because the development of such a system provides a key incentive for faculty to receive review and acknowledgement of their community contributions in the "teaching" dimensions of scholarship. Without this recognition and assessment provided by the hydrology education community, it is less likely that significant progress will be made on the development of curriculum materials. The survey respondents agreed that hydrology instruction should be integrated with CUAHSI HIS and other cyberinfrastructure (CI) activities within hydrology to take the advantage of progress made by different groups. A major constraint in creating a $\mathrm{CI}$ is to get a critical mass devoted to this effort to contribute high quality material for student learning. Similarly, there needs to be standard mechanism or framework for contributing to this community effort to avoid repetition or incompatible module submissions. 


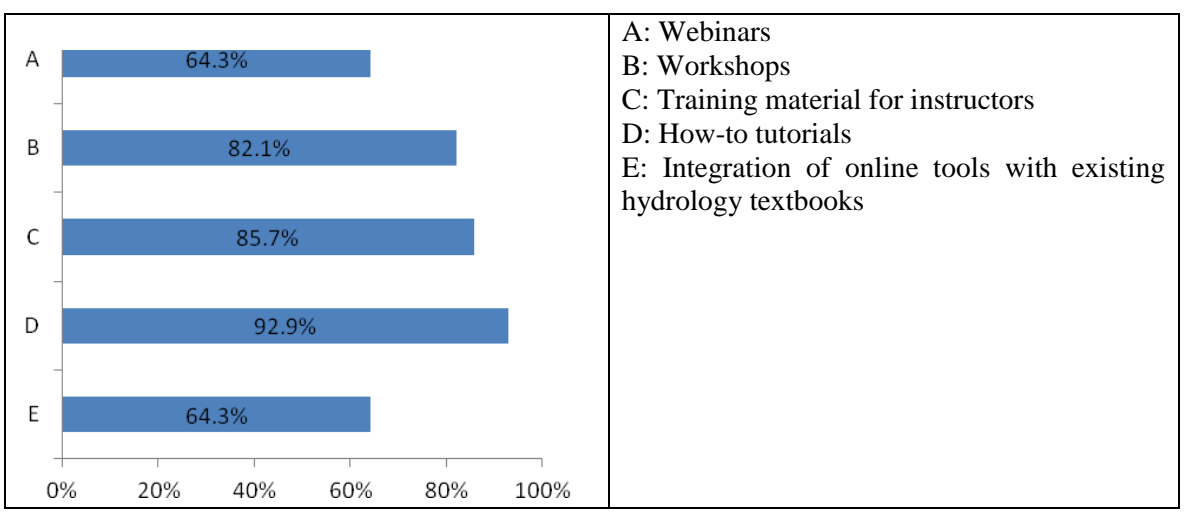

Fig. 2. Percentages of workshop participant survey respondents $(N=37)$ rating specific learning community cyberinfrastructure training and equipping resources as important for their personal applications.

\subsubsection{Prioritize community and instructor training approaches}

Several mechanisms (Fig. 2) can be used to train instructors on using the cyberinfrastructure for curriculum development, publishing, and sharing. Workshop participants identified "how-to tutorials" as the most important type of training, but all of the other alternatives (webinars, workshops, instructor training, and integration of tools with textbooks) were also identified as important by a majority of participants. Besides the mechanisms listed in Fig. 2, written comments by participants identified short hands-on workshop as an important training approach for instructors. One cited example of such a workshop is the "On the Cutting Edge" workshop hosted by SERC (http://serc.carleton.edu/NAGTWorkshops/ about.html). Also, the American Society of Civil Engineers has approached the challenge of "integration" of STEM education through the creation of the ExCEEd Teaching Model (Estes et al., 2005, http://www.asce.org/exceed/), which emphasizes integration of classroom activities and hands-on activities with lecture materials.

\subsection{Discussion on design learning modules}

The workshop participants were asked to identify hydrology learning outcomes that can be accomplished using specific currently available public domain data and modeling tools, categorize those learning outcomes by academic level, and then design two simple data and modeling modules, one for lower-division hydrology and one for upper-division hydrology, to accomplish at least one of the learning outcomes they described.

The participants identified the following design criteria and objectives for cyberlearning module content and structure. First, the teaching modules should be developed such that the instructor or students should have the choice to mix and match them based on their teaching objectives or learning outcomes. Second, the modules should be flexible enough to be implemented on multiple watersheds so students can compare or contrast their results by using the same modules on different watersheds. While flexibility in the choice of modules is welcomed, some participants also emphasized the importance of how these modules should be designed to invoke critical thinking among students at undergraduate level instead of just producing numbers for comparison. Third, modules at graduate level should involve more quantitative analysis so students can develop and test hypotheses, conduct uncertainty analyses, address issues related to missing data, and answer research type questions. Fourth, participants proposed the development of simulation or gaming tools in the form of a "virtual Earth" where students can change variables such as land use and climate to investigate the effect of such changes on the hydrologic cycle and rapidly visualize results. Fifth, the idea of linking web learning modules with field work was also received positively by most participants at the workshop. Sixth, several participants emphasized the interdisciplinary nature of hydrologic education (e.g., science versus engineering or hydrogeology versus surface water) and the necessity of developing cyberlearning modules that reach these different education objectives.

\subsection{Discussion on online learning and curriculum development environment}

The workshop participants were directed to consider a time in the near future when an online resource becomes available for hydrology faculty to collaborate on the development and publication of learning modules based on data analysis and modeling. This environment will also host community training activities for students and instructors. The participants sketched a design, including specific design requirements, for a system that the participants would find useful for their courses on a regular basis. Bearing in mind that the system must be very useable and affordable to build and maintain, 
the participants were asked to identify the few top-priority functions and capabilities that the system must have.

The participants identified the following design criteria and objectives for the online learning and curriculum development environment. First, although the web learning environment can serve as a community gateway for data, models and teaching or learning modules, care should be taken to link all the available resources in the system to learning objectives for students. This will, to some extent, avoid overwhelming users with the information available in the system. Second, there are lots of portals to get data and models on the web. Efforts should be made as much as possible to avoid duplication and incorporate what is already available and working. Third, there is a need to bring consensus among the community on what resources should be used in classrooms, and whether to provide raw or pre-processed (error free) data to students. On one hand, provision of clean datasets will enable students to focus more on the learning concepts rather than data processing, but on the other hand, students will not experience the actual process of using real data in research and practice. Fourth, participants emphasized "second hand" modeling experience utilizing an online environment where users can upload their completed projects or case studies so others can just use these "canned" models to answer specific questions. Fifth, while the online learning environment should be open to all, it is critical to have different access depending on the role of users. For example, contributors or faculty should have a higher level access compared to endusers such as students who can only use the resources rather than creating or modifying the content.

\section{Conclusions}

The participants in the university hydrology community surveys and the workshop communicated a general consensus on the challenges and priorities for data and modeling driven cybereducation (DMDGC) approaches in university hydrology education. This consensus is summarized below.

- A community-based curriculum material development effort will be a worthwhile use of the community's time and energy, if it is implemented such that incentives and cost/benefit balances motivate individual faculty members to actively participate (we need critical mass).

- Bridging the gap from lower-division undergraduate hydrology (usually qualitative hydrology) to upperdivision undergraduate hydrology (which needs to be quantitative) is a key challenge; cybereducation approaches should address both levels.

- Any new cyberinfrastructure must connect with geosciences, engineering, and hydrology education cyberinfrastructures and communities that already exist, because some excellent work is already being done; do not reinvent the wheel on concepts or dissemination.
- A focus on teaching hydrology concepts and modeling skills through DMDGC approaches must be maintained, and a tendency to create "black box" tools avoided.

- Geospatial and other data visualization features are particularly desirable.

- Public domain and open content data and toolsets are strongly preferred, but some industry-standard proprietary software tools and proprietary training materials may be necessary and desirable in the curriculum.

- Curriculum cyberinfrastructure must be carefully implemented to maintain rigorous contribution quality and interoperability standards; this will be particularly essential if modules from different authors are to be combined in sequences to teach hydrology concepts.

- Module publication and search functionality is essential, but a more streamlined and accessible method of accessing context-specific and local hydrology data is also important.

- Built-in assessment and feedback functionality for modules is essential.

- Workshops and tutorials are the preferred methods of training for the new systems.

- Integration with the existing CUAHSI-HIS, HUBzero, MOCHA, SERC, and NSDL systems is strongly supported as a best practice within the USA.

- DMDGC approaches should be used to complement, not replace, traditional lecture and body of knowledge. These approaches should be connected directly to learning outcomes and concepts.

- Reusability, adaptability, flexibility, and modifiability of DMDGC content is essential to facilitate longevity and allow for incremental cumulative gains in content quality; without these properties, the modules will rapidly become obsolete as digital technology changes, even if the modules are broadly disseminated, well designed, easily adopted, and positively reviewed.

- The hydrology concepts will not change, but the context within which these concepts are taught may differ with different disciplines and geographic locations. The same CI design criteria of searchability, modularity and interoperability, which facilitate reuse, adaptation, and modification of curriculum materials to prevent obsolescence, are also the essential qualities that will allow these materials to transcend disciplinary, cultural, national, geographic, and linguistic barriers as the broader global geosciences community uses the CI to "mix and match" and continually re-develop and republish materials. 
The body of STEM literature and the results of these surveys and the workshop combine to provide strong support for a community-based effort to develop data and modeling driven cybereducation module content that can be integrated with traditional lecture materials in the university hydrology classroom to enhance learning outcomes and to better prepare students for research and professional careers. This community support towards developing data and modeling driven curriculum is encouraging, but serious conceptual, practical and technical challenges remain unsolved. Leadership will be required from the US and international university hydrology education communities to realize this vision and overcome the identified challenges. An international approach to the challenge should be encouraged, through communities of practice that already engage international participants.

Conceptually, the integration of DMDGC with lecturebased pedagogies will involve a modified approach that emphasizes a hybrid of hands-on activities alongside lecture approaches (e.g., Estes et al., 2005 or Lesko, 2011). For example, a hydrology course can be built by implementing MOCHA-style modules and textbook-driven lecture content, which can then be integrated with corresponding DMDGC modules in which students use data and models to solidify the concepts learned from the lecture. A body of STEM literature provides guidance on how to best implement and assess this integrated curriculum.

Practically, the ability of an instructor to adopt a module in an existing course will depend on the time and resources needed to make the change. An instructor familiar with one type of analysis tool (e.g., MS Excel) and data must climb a learning curve to teaching, using a module involving different data and tools. This learning curve will be much easier in the future if the community makes available the necessary training and high-quality content, and if the community's experts keep this content updated and current. The authors argue that the most important practical consideration is the incentivization and resourcing of the ongoing development and maintenance of DMDGC content by the experts who generate it. This requires some level of funding, but more importantly it requires formal assessment of impact and a strong recognition by the hydrology education community of the value of this type of scholarly activity and authorship.

Technically, the community still lacks a fully adequate cyberinfrastructure and online environment capable of supporting this kind of digital learning content. Therefore, before DMDGC curricula can be developed and implanted in classrooms, it is critical to develop an online system that the university hydrology education community is willing and able to utilize. This opinion paper provides the background and community-derived design criteria necessary to develop the online framework for DMDGC applications in the university hydrology classroom.
Supplementary material related to this article is available online at: http://www.hydrol-earth-syst-sci.net/ 16/2393/2012/hess-16-2393-2012-supplement.pdf.

Acknowledgements. The authors acknowledge the participation and input of all the attendees (see supplementary materials) at the workshop, and the individuals who responded to online surveys. Review comments from A. Jonoski are greatly appreciated. This material is based upon the work supported partially by the US National Science Foundation (NSF) under the Grant Number: 1035985. Any opinions, findings, and conclusions or recommendations expressed in this material are those of the authors and do not necessarily reflect the views of NSF.

Edited by: S. Uhlenbrook

\section{References}

Abbott, M. B., Solomatine, D., Minns, A. W., and Van Nievelt, W.: Educating and training in hydroinformatics, J. Hydraul. Res., 32, Iss. sup. 1, 1994.

Borgman, C. L., Abelson, H., Dirks, L., Johnson, R., Koedinger, K. R., Lynch, C. A., Oblinger, D. G., Pea, R. D., Salen, K., Smith, M. S., and Szalay, A.: Forthcoming, Fostering Learning in the Networked World: The Cyberlearning Opportunity and Challenge, A 21st Century Agenda for the National Science Foundation, Report of the NSF Task Force on Cyberlearning, Office of Cyberinfrastructure and Directorate for Education and Human Resources: National Science Foundation, http://www. nsf.gov/pubs/2008/nsf08204/index.jsp (last access: July 2012), 2008.

Boyer, E. L.: Scholarship reconsidered: priorities of the professorate, Carnegie Foundation for the Advancement of Teaching, Princeton, NJ, USA, 1990.

DiSessa, A.: Changing Minds: Computers, Learning, and Literacy, MIT Press, Cambridge, MA, 2000.

Duderstadt, J. J.: Engineering for a Changing World: A Roadmap to the Future of Engineering Practice, Research, and Education, Millennium Project, University of Michigan, Ann Arbor, MI, 2007.

Estes, A. C., Welch, R. W., and Ressler, S. J.: The ExCEEd Teaching Model, J. Prof. Issue. Eng. Educ. Pract., 131, 218-222, 2005.

Jonoski, A. and Popescu, I.: Distance Learning in Support of Water Resources Management: An Online Course on Decision Support Systems in River Basin Management, Water Resour. Manage., 26, 1287-1305, 2012.

Kaput, J., Hegedus, S., and Lesh, R., Technology becoming infrastructural in mathematics education, in: Foundations for the Future in Mathematics Education, edited by: Lesh, R., Hamilton, E., and Kaput, J., Routledge, London, 173-192, 2007.

Lesko, C. J.: Blending on-campus and online experiences through the use of virtually immersive technologies, J. Online Eng. Educ., 2, 1-10, 2011.

Manduca, C., Baer, E., Hancock, G., Macdonald, R. H., Patterson, S., Savina, M., and Wenner, J.: Making Undergraduate Geoscience Quantitative, EOS Transactions of the American Geophysical Union, v. 89, no. 16, 2008. 
McKagan, S. B., Perkins, K. K., Dubson, M., Malley, C., Reid, S., LeMaster, R., and Wieman, C. E.: Developing and researching $\mathrm{PhET}$ simulations for teaching quantum mechanics, Am. J. Phys., 76, 406-417, 2008.

Melsa, J. L., Rajala, S. A., and Mohsen, J. P.: Creating a culture for scholarly and systematic innovation in engineering education, J. Eng. Educ., 98, 209, 2009.

Molkenthin, F., Holz, P. K., Belleudy, P., Jozsa, J., Price, R. K., and van der Veer, P.: HydroWeb: WWW based collaborative engineering in hydroscience - a European education experiment in the Internet, J. Hydroinform., 3, 239-243, 2001.

Morell, L. and DeBoer, J.: The Engineering Professor of 2020: the Forgotten Variable, ASEE National Conference Proceedings, Louisville, Kentucky June 2010 AND ASEE Global Colloquium of Engineering Education Proceedings, Singapore, October 2010.

National Academy of Engineering: Educating the engineer of 2020: Adapting engineering education to the new century, The National Academics Press, Washington, DC, 2005.

National Academies of Science: The Engineer of 2020: Visions of Engineering in the New Century, The National Academies Press, Washington, DC, 2004.

National Academy of Sciences, National Academy of Engineering, and Institute of Medicine: Rising Above the Gathering Storm: Energizing and Employing America for a Brighter Economic Future., The National Academies Press, Washington, DC, 2007.

NSF Cyberinfrastructure Council: Cyberinfrastructure Vision for 21st Century Discovery, National Science Foudnation, http://www.nsf.gov/pubs/2007/nsf0728/index.jsp (last access: July 2012), 2007.
Popescu, I., Jonoski, A., Bhattacharya, B., and Keuls, C.: On-Line Competence Based Learning in Hydroinformatics at UNESCOIHE, Proceedings of the 8th International Conference on Hydroinformatics, Concepción, Chile, January 2009.

Popescu, I., Jonoski, A., and Bhattacharya, B.: Experiences from online and classroom education in hydroinformatics, Hydrol. Earth Syst. Sci. Discuss., 9, 1311-1333, doi:10.5194/hessd-91311-2012, 2012.

Price, R. K., Popescu, I., Jonoski, A., and Solomatine, D. P.: Fifteen years of experience in hydroinformatics at UNESCO-IHE Institute for Water Education, Proceedings of the 7th International Conference in Hydroinformatics, Nice, France, Research Publishing, 3101-3108, 2006.

Price, R. K., Bhattacharya, B., Popescu, I., and Jonoski, A.: Flood modelling for management: UNESCO-IHE's online course in hydrology, (link to the bulletin issue) World Meteorological Organisation Bulletin 56, 102-106, WMO, also see http: //www.unesco-ihe.org/Flood-Management-Education-Platform/ Flood-Modelling-for-Management2 (last access: 18 May 2012), 2007.

Special Report: The Research Agenda for the New Discipline of Engineering Education, Washington, DC, J. Eng Educ., 95, 259261, 2006.

Wagener, T., Weiler, M., McGlynn, B., Gooseff, M., Meixner, T., Marshall, L., McGuire, K., and McHale, M.: Taking the pulse of hydrology education, Hydrol.1 Process., 21, 1789-1792, doi:10.1002/hyp.6766, 2007. 